\title{
On the relative importance of the effects of selection and complementarity as drivers of diversity-productivity relationships in Mediterranean shrublands
}

\author{
Nicolas Montès, Fernando T. Maestre, Christine Ballini, Virginie Baldy, Thierry Gauquelin, \\ Mathieu Planquette, Stéphane Greff, Sylvie Dupouyet and Jean-Baptiste Perret
}

N. Montès (nicolas.montes@univ-provence.fr), C. Ballini, V. Baldy, T. Gauquelin, M. Planquette, S. Greff, S. Dupouyet and J.-B. Perret, Inst. Méditerranéen d'Ecologie et de Paléoécologie (IMEP), UMR CNRS 6116, Univ. Aix-Marseille, Case 421, Faculté des Sciences et Techniques de St Jérôme, Avenue Escadrille Normandie Niemen, FR-13397 Marseille Cedex 20, France. - F. T. Maestre, Univ. Rey Juan Carlos, Area de Biodiversidad y Conservación, Escuela Superior de Ciencias Experimentales y Tecnologia, C/ Tulipán s/n, ES-28933 Móstoles, Spain.

\begin{abstract}
Extensive research has been devoted to understanding the role of biodiversity as a driver of ecosystem functioning. However, no previous study has evaluated the relative contribution of complementarity and selection to productivity in shrublands. We have attempted to do this for a Mediterranean shrubland dominated by Quercus coccifera, Cistus albidus, Ulex parviflorus and Rosmarinus officinalis. We found a highly significant and linear positive relationship between productivity and species richness. No selection effect was apparent, but both the complementarity and net effects were highly significant. The magnitude of these effects increased from two to three species, but became non-significant in the four-species mixtures. Analysis of pairwise interactions revealed that legumes did not promote overyielding. Complementarity was mostly driven by Cistus, which always performed better when growing with other species than when growing with conspecifics. Our results are an addition to the still scarce literature dealing with diversityproductivity relationships in communities dominated by woody species, and show that methodologies commonly used to assess complementarity may not provide a precise estimation when a given species has negative effects on its conspecifics.
\end{abstract}

Because of an increasing concern regarding the ecological consequences of its decline, biodiversity has been the subject of an abundant portfolio of studies devoted to understanding its role in ecosystem functioning (summarised by Kinzig et al. 2002, Loreau et al. 2002, Hooper et al. 2005). This large body of research has led to a consensus that ecosystem properties depend greatly on biodiversity attributes such as species richness, functional characteristics, and the spatio-temporal distribution and abundance of individuals (Hooper et al. 2005). However, nearly all empirical research linking biodiversity and ecosystem functioning has focused on terrestrial plant communities with low structural complexity, mostly grasslands, model microbial systems, and aquatic communities, from both freshwater and marine environments (Hector et al. 1999, Engelhardt and Ritchie 2002, Hedlund et al. 2003, Maestre and Reynolds 2006). This limits our ability to make confident generalizations on the functional role of biodiversity, or to extrapolate the results obtained so far to other communities (Giller et al. 2004).

In the majority of the experiments carried out so far, the productivity of small experimental units containing monocultures of given species were compared to those containing mixtures of different species. These experimental protocols highlighted an effect of diversity, sometimes negative (McNaughton 1993), sometimes null, but often positive on the productivity of the community (Loreau 2000, Groner and Novoplansky 2003). In a recent review, Hooper et al. (2005) concluded that productivity generally increases with diversity. Two main mechanisms have been proposed to explain this positive relationship: complementarity and sampling effect (Hooper et al. 2005). Individuals in monocultures compete for resources in the same way (Tilman et al. 1997b), but in a mixture, because of niche differentiation (Leibold 1995), higher diversity leads to higher resource use, increasing total community biomass (Stevens and Carson 2001). A contrasting theory, referred to as 'sampling effect', hypothesized that the higher productivity of a mixture results in a statistical effect that increases the probability of selecting some highly productive species (Wardle 1998, Huston et al. 2000). The later is related to the 'selection effect', which refers to the trend for species interactions in mixtures to 'select for' or favor species with specific traits (Loreau and Hector 2001).

Interestingly, little effort has been devoted to testing the predictions of various hypotheses describing relationships 
between biodiversity and ecosystem processes in natural and semi-natural ecosystems dominated by shrub species (Troumbis and Memtsas 2000), probably because of difficulties in obtaining precise estimations of their productivity in short-term studies. However, these ecosystems account for a substantial part of total land cover, and are particularly relevant in arid, semi-arid, and dry-subhumid areas (Reynolds et al. 2007). Furthermore, the cover of shrub-dominated ecosystems is increasing worldwide, a process with important implications for the structure and functioning of terrestrial ecosystems (Van Auken 2000, Berlow et al. 2002, Anthelme et al. 2007). Therefore, it is not surprising that increasing our knowledge on the relationships between diversity and ecosystem functioning in natural shrublands has been identified as a priority for biodiversity research (Hooper et al. 2005). To our knowledge, no previous study has evaluated the relative contributions of the effects of complementarity and selection (sensu Loreau and Hector 2001) as drivers of the biodiversity effect on ecosystem functioning in shrublands. We have attempted to do this for a Mediterranean shrubland dominated by Quercus coccifera, Cistus albidus, Ulex parviflorus and Rosmarinus officinalis, which cover large expanses in the Mediterranean Basin (Montès et al. 2004, Larcheveque et al. 2006, Baeza et al. 2007), under natural conditions. The aims of the study were to (1) evaluate the relationship between species richness and productivity, and (2) assess the relative importance of the effects of complementarity and selection as drivers of this relationship.

\section{Methods}

\section{Study area}

The study was carried out in the Chaine de l'Etoile $\left(43^{\circ} 21^{\prime} 50^{\prime \prime} \mathrm{N}, 5^{\circ} 24^{\prime} 20^{\prime \prime} \mathrm{E}\right)$, located $5 \mathrm{~km}$ northeast of Marseille (Bouches-du-Rhône, France). The climate is Mediterranean, with a mean annual temperature and rainfall of $15^{\circ} \mathrm{C}$ and $570 \mathrm{~mm}$, respectively, and a pronounced summer drought. Derived from limestone, soils are classified as rendzina (FAO 1988). They are shallow, with depths of less than $20 \mathrm{~cm}$, have a high percentage of stones (the fraction below $2 \mathrm{~mm}$ is $33.4 \% \pm 1.4$, mean \pm $\mathrm{SE}, \mathrm{n}=30$ ), and their $\mathrm{C}, \mathrm{N}$ and $\mathrm{C} / \mathrm{N}$ values are $2.21 \% \pm$ $0.13, \quad 0.18 \% \pm 0.01$ and $12.25 \pm 0.23$, respectively (means $\pm S E, n=15$ ). The last fire occurred in 1997, and current vegetation is a shrubland dominated by Cistus albidus, Quercus coccifera, Ulex parviflorus and Rosmarinus officinalis (Supplementary material Appendix 1). The occurrence of fires, soil characteristics and dominant species are representative of calcareous shrublands located around the Mediterranean coast (Montès et al. 2004, Larcheveque et al. 2005, 2006).

\section{Field sampling and productivity estimation}

For this study we considered a total of 15 composition levels, resulting from the monocultures and all possible combinations of the four dominant species (Cistus, Quercus, Ulex and Rosmarinus). We estimated biomass and productivity indirectly with the point intercept method (Jonasson 1988), which is based on the relationship between plant biomass and the number of contacts with a pin (metal rod of $2 \mathrm{~mm}$ diameter) passed vertically through the vegetation to the ground (Supplementary material Appendix 1). This approach was preferred over destructive sampling to avoid the high degree of disturbance associated with these measurements, and because it has been successfully employed to estimate biomass and productivity in Mediterranean shrublands (Troumbis and Memtsas 2000). We laid out a total of 64 permanent transects, $2 \mathrm{~m}$ in length with sampling points at $10-\mathrm{cm}$ intervals, following a stratified random design, with transects randomly allocated to each of the 15 species combinations. Because of the relatively small size of the studied area (we limited it to about 4 ha to avoid changes in environmental conditions), it was not possible to find more than three replicates for some species combinations (the number of replicated transects varied between three and six). We took measurements of pin contacts along the same transects in March and June 2006, before and after the main growing season.

We calibrated the relationships between pin contacts and biomass in 15-25 individuals of the species studied. We placed $1 \times 1 \mathrm{~m}$ quadrats with a $10 \times 10 \mathrm{~cm}$ grid above the canopies of individuals covering a wide range in size $(0.2-$ $1.4 \mathrm{~m}$ height), and we noted the number of contacts at each sampling point (a sampling point represents a $100 \mathrm{~cm}^{2}$ sampling area). For Ulex, it was sometimes difficult (because of its dense canopy) to see all contacts (up to 40 pin contacts per sampling point). Thus, we also noted the height of the highest contact for this species. After the pin measurements, we clear-cut, oven dried $\left(75^{\circ} \mathrm{C}\right.$ for two days) and weighed all individuals. The relationships between these measurements and aboveground biomass were obtained with linear regressions of the form $\mathrm{B}=\mathrm{aX}$. These were in all cases highly significant $\left(p<0.0001, R^{2} \geq 0.83\right.$; Table 1), and thus we used the number of pin contacts or height of the highest pin contact in the case of Ulex, to estimate productivity under field conditions. It was obtained as $\left(B_{2}-B_{1}\right) /\left(B_{1}\right)$, where $B_{1}$ and $B_{2}$ are the standing biomass in March and June, respectively. Productivity was estimated separately for each species and transect.

Table 1. Simple linear regressions between total biomass ( $\mathrm{g}$ ) and either pin contacts (number) or height (in $\mathrm{cm}$ ).

\begin{tabular}{|c|c|c|c|c|c|}
\hline Species & Dependent variable & Independent variable & Constant & $\mathrm{R}^{2}$ & $p$ \\
\hline Cistus albidus $(n=25)$ & total biomass & total pin contacts & 2.7902 & 0.97 & $<0.0001$ \\
\hline Quercus coccifera $(n=20)$ & total biomass & total pin contacts & 2.1238 & 0.94 & $<0.0001$ \\
\hline Rosmarinus officinalis $(n=21)$ & total biomass & total pin contacts & 1.5529 & 0.91 & $<0.0001$ \\
\hline Ulex parviflorus $(n=15)$ & total biomass & height & 0.4716 & 0.97 & $<0.0001$ \\
\hline Ulex parviflorus $(n=11)$ & total biomass & total pin contacts & 1.4913 & 0.83 & $<0.0001$ \\
\hline
\end{tabular}




\section{Assessment of biodiversity effects and species} interactions

The evaluation of all possible species combinations allowed us to distinguish between the effects of complementarity and selection using the method proposed by Loreau and Hector (2001). According to this approach, the net biodiversity effect (NE) in a community of $k$ species is:

$\mathrm{NE}=\mathrm{CE}+\mathrm{SE}=\mathrm{k} \times \overline{\Delta \mathrm{RY}} \times \overline{\mathrm{Y}_{\mathrm{M}}}+\mathrm{k} \times \operatorname{cov}\left(\Delta \mathrm{RY}, \mathrm{Y}_{\mathrm{M}}\right)$

where $\mathrm{CE}$ and $\mathrm{SE}$ are the complementarity and selection effects, respectively. $\Delta R Y$ is the deviation from expected relative yield of a given species in the mixture, calculated as the difference between expected and observed relative yields. The latter is the ratio of its yield in mixture and monoculture; the expected relative yield is given by its relative abundance. The complementarity effect is proportional to the average of $\Delta R Y$ over all species in the mixture and to $Y_{M}$, whereas the selection effect is proportional to the covariance of $\Delta R Y$ and yield of the species in monoculture $\left(\mathrm{Y}_{\mathrm{M}}\right)$.

Although extremely useful to separate complementarity from selection effects, the Loreau and Hector (2001) approach cannot distinguish direct facilitation from niche differentiation as the mechanism for driving complementarity effects. To gain additional insight into the mechanisms underlying the responses observed in our study, we estimated the magnitude and direction of biotic interactions with the RII index (Armas et al. 2004). It was calculated as $\left(\mathrm{Y}_{\mathrm{i}, \mathrm{j}} \mathrm{Y}_{\mathrm{i}, \mathrm{i}}\right) /\left(\mathrm{Y}_{\mathrm{i}, \mathrm{j}}+\mathrm{Y}_{\mathrm{i}, \mathrm{i}}\right)$, where $\mathrm{Y}_{\mathrm{i}, \mathrm{i}}$ and $\mathrm{Y}_{\mathrm{i}, \mathrm{j}}$ are the productivity of species $i$ in monospecific stands (average of all the transects), and that of species $i$ in mixture with species $j$. RII is a symmetrical index around 0 , and ranges from -1 to +1 . Negative and positive effects are indicative of competition and facilitation, respectively.

\section{Statistical procedures}

We evaluated the relationships between (1) biomass of shrub species and number of pin contacts or height and (2) shrub diversity and productivity, using linear regressions. We used one-way ANOVA and post-hoc Turkey to test in complementarity, selection effect and net effects among richness levels, and t-tests to evaluate whether RII, complementarity, selection effect, and net effect values differed from 0 . Prior to these analyses, we checked the normality and homoscedasticity of the data with ShapiroWilk and Levene tests, respectively. We conducted all statistical analyses with Minitab for Windows (ver. 13).

\section{Results}

We found a highly significant and linear positive relationship between productivity and species richness (Fig. 1). No selection effects were apparent, but both the complementarity and net effects were highly significant (Fig. 2; oneway ANOVA; complementarity: $F_{2,45}=5.96, p=0.005$; net effect: $\left.F_{2,45}=4.36, p=0.019\right)$. The magnitude of this effect increased from two to three species, but became nonsignificant in the four-species mixtures. Pairwise compar-



Figure 1. Relationship between the number of shrub species and productivity in the studied shrubland. The model fitted to the data (solid line; $y=0.44 x-0.13)$ was highly significant $\left(R^{2}=0.4\right.$, $\left.\mathrm{F}_{1,64}=41.34, \mathrm{p}<0.001, \mathrm{n}=64\right)$.

isons using the RII index showed that all the species had a positive effect (trend for Rosmarinus) on the productivity of Cistus (Fig. 3). This species positively affected the Quercus productivity. None of the species evaluated had significant effects on the productivity of either Ulex or Rosmarinus, although it is interesting to note a clear trend towards a negative effect of Cistus on Ulex productivity.

\section{Discussion}

Our results show a clear positive relationship between species diversity and productivity in a Mediterranean shrubland, and indicate that this effect is mostly due to complementarity among the interacting species. They agree with studies showing the positive effect of species richness on the productivity of plant communities in artificial microcosms (Dukes 2001), semi-natural grasslands (Tilman et al. 1997a, Hector et al. 1999, van Ruijven and Berendse 2005) and woody shrublands (Troumbis and Memtsas 2000). The total number of species involved in our study was relatively low when compared to other studies, for which the maximum diversity tested artificially was as high as 30 species (Tilman et al. 1997a). However, the probability of sampling effect increases when conducting studies with so many species. In shrublands such as those studied, we can assume that interactions between species involve a small number of individuals because of their size and density. It is interesting to note that our results mimic those obtained for the large-scale BIODEPTH experiment (Hector et al. 1999), suggesting that the maximum positive effects of biodiversity on the aboveground biomass of herbaceous communities were reached with just four species (Giller and O'Donovan 2002).

The additive partitioning method used revealed that the positive relationship between diversity and productivity was related to a highly significant complementarity effect. While legumes are assumed to play an important role in overyielding (Huston et al. 2000, Giller and O'Donovan 2002, Temperton et al. 2007), we did not find significant selection effects despite the presence of Ulex in the mixtures (Fig. 2). As found by Hector et al. (2007), complementarity 

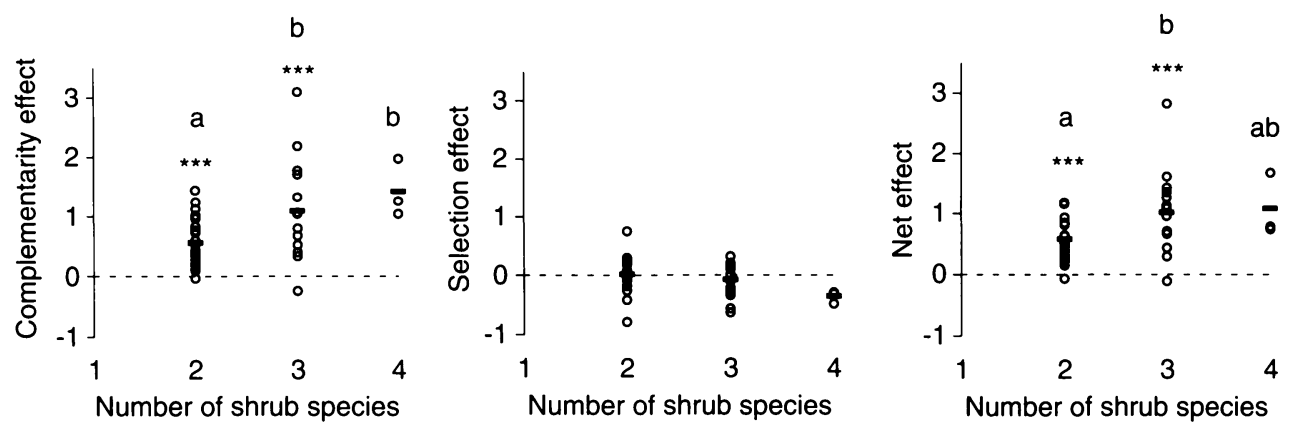

Figure 2. Complementarity, selection and net effects for the three species richness levels evaluated. Asterisks denote significant differences from 0 in each effect ( $t$-test; $\left.{ }^{*}, p<0.05 ;{ }^{* *}, p<0.01 ;{ }^{* * *}, p<0.001\right)$. Different letters denote significant differences between richness levels $(\mathrm{p}<0.05$, Tukey test after one-way ANOVA).

was not driven by legumes, something confirmed by the RII analyses. Despite having high $\mathrm{N}$-fixation rates in Mediterranean shrublands (Ballini and Bonin 1995, GimenoGarcia et al. 2001), Ulex had only a positive effect on Cistus, but that effect was no greater than those promoted by other species (Fig. 3). Albeit non-significantly, Ulex was negatively affected by Cistus and Rosmarinus. We hypothesize that this effect may be promoted by the allelochemicals produced by these two species (Robles and Garzino 1998, Gómez-Aparicio et al. 2004), which could inhibit $\mathrm{N}_{2-}$ fixation in Ulex. Along similar lines, Schimel et al. (1998) found that Populus balsamifera tannins inhibited $\mathrm{N}_{2-}$ fixation in Alnus tenuifolia.

Productivity of Cistus was always higher in mixtures than in monoculture. Even if we cannot fully exclude mechanisms such as the presence of more productive Cistus genotypes in the mixtures (Pachepsky et al. 2007), we suggest that this result may have been caused by strong intra-specific competition or allelophatic effects, something already revealed by experimental work on the potential autotoxicity of Cistus albidus (Robles et al. 1999). It is interesting to note that the higher productivity observed in the two-species mixtures can only be partially attributed to the complementarity effect (sensu Loreau and Hector 2001); when Cistus is involved, the increase in productivity observed does not correspond to a real positive effect of other species, but rather to an elimination of intraspecific negative interactions among Cistus individuals. This 'suppression effect' cannot either be considered as a selection effect because it does not correspond to a positive or negative effect of a species in a mixture, but rather corresponds to a decrease of negative intraspecific interactions. This result emphasizes that the commonly used Loreau and Hector (2001) protocol may not always provide a precise estimation of complementarity as a mechanism because it cannot discriminate those cases where a given species has a negative effect on its conspecifics. Therefore, our results indicate the suitability of incorporating additional RII-like analyses in biodiversity-productivity studies in order to elucidate situations such as found in this study.

Given the observational nature of our study, we have been unable to ascertain the mechanisms underlying the diversity-productivity relationships observed, and some unaccounted for factors may have affected our interpretation of these relationships. For instance, possible differences in the age of individuals may have an impact on the estimation of productivity because it generally decreases with age. However, the use of productivity instead of production in our study minimized this effect, as well as those resulting from differences in the size or density of individuals. Furthermore, by studying a spatially limited area, we avoided bias resulting from differences in soil and microclimatic conditions, reducing the potential impact of environmental heterogeneity on our results. Our study is an

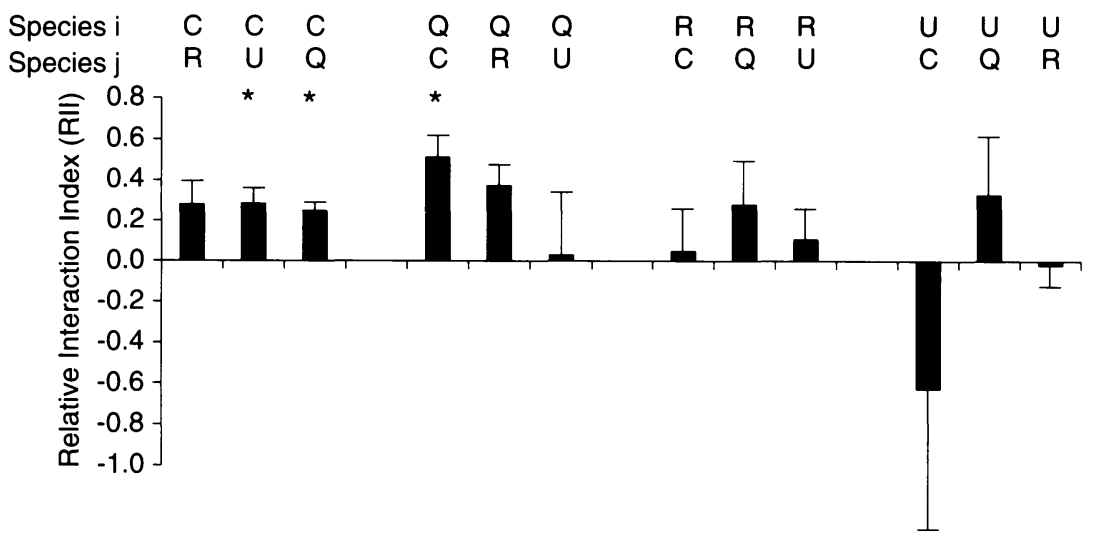

Figure 3. Relative interaction index (RII) measuring productivity of a species $\mathrm{i}$ in monoculture relative to its productivity in mixture with a species $\mathrm{j}$. Asterisks indicate significant differences from 0 ( $\mathrm{t}$-test, $\mathrm{p}<0.05)$. Data represent means $\pm \mathrm{SE}(\mathrm{n}=3-6)$. $\mathrm{C}=$ Cistus albidus, $\mathrm{R}=$ Rosmarinus officinalis, $\mathrm{U}=$ Ulex parviflorus and $\mathrm{Q}=$ Quercus coccifera. 
addition to the still scarce literature dealing with diversityproductivity relationships in communities dominated by woody species (Troumbis and Memtsas 2000, Balvanera and Aguirre 2006). Although experimentally and logistically challenging, studies that focus on these species are crucial in order to advance our understanding of the importance of biodiversity as a driver of ecosystem functioning in terrestrial ecosystems.

Acknowledgements - We thank Nicholas J. Gotelli and Catherine Potvin for comments and suggestions on a previous version of the manuscript. FTM was supported by a Ramón y Cajal contract from the Spanish Ministerio de Educación y Ciencia, co-funded by the European Social Fund, by the Comunidad de Madrid grant REMEDINAL (S-0505/AMB/0335) and by the Fundación BBVA grant INTERCAMBIO (BIOCON 06_039). We also thank M. Paul for improving the English version.

\section{References}

Anthelme, F. et al. 2007. Shrub encroachment in the Alps gives rise to the convergence of sub-alpine communities on a regional scale. - J. Veg. Sci. 18: 355-362.

Armas, C. et al. 2004. Measuring plant interactions: a new comparative index. - Ecology 85: 2682-2686.

Baeza, M. J. et al. 2007. Human disturbance and environmental factors as drivers of long-term post-fire regeneration patterns in Mediterranean forests. - J. Veg. Sci. 18: 243-252.

Ballini, C. and Bonin, G. 1995. Nutrient cycling in some Ulex parviflorus Pourr scrubs in Provence (southeastern France). 2. Nutrient release from decomposing litter. - Eur. J. Soil Biol. 31: 143-151.

Balvanera, P. and Aguirre, E. 2006. Tree diversity, environmental heterogeneity, and productivity in a Mexican tropical dry forest. - Biotropica 38: 479-491.

Berlow, E. L. et al. 2002. Shrub expansion in Montane meadows: the interaction of local-scale disturbance and site aridity. - Ecol. Appl. 12: 1103-1118.

Dukes, J. S. 2001. Productivity and complementarity in grassland microcosms of varying diversity. - Oikos 94: 468-480.

Engelhardt, K. A. M. and Ritchie, M. E. 2002. The effect of aquatic plant species richness on wetland ecosystem processes. - Ecology 83: 2911-2924.

FAO 1988. World reference base for soil resources. - Int. Soc. of Soil Sci.

Giller, P. S. and O'Donovan, G. 2002. Biodiversity and ecosystem function: do species matter? - Biology and environment: Proc. R. Irish Acad. 102B: 129-139.

Giller, P. S. et al. 2004. Biodiversity effects on ecosystem functioning: emerging issues and their experimental test in aquatic environments. - Oikos 104: 423-436.

Gimeno-Garcia, E. et al. 2001. Influence of mediterranean shrub species on soil chemical properties in typical Mediterranean environment. - Comm. Soil Sci. Plant Anal. 32: 1885-1898.

Gómez-Aparicio, L. et al. 2004. Applying plant facilitation to forest restoration: a meta-analysis of the use of shrubs as nurse plants. - Ecol. Appl. 14: 1128-1138.

Groner, E. and Novoplansky, A. 2003. Reconsidering diversityproductivity relationships: directness of productivity estimates matters. - Ecol. Lett. 6: 695-699.

Hector, A. et al. 1999. Plant diversity and productivity experiments in European grasslands. - Science 286: 1123-1127.

Hector, A. et al. 2007. Biodiversity and ecosystem functioning: reconciling the results of experimental and observational studies. - Funct. Ecol. 21: 998-1002.
Hedlund, K. et al. 2003. Plant species diversity, plant biomass and responses of the soil community on abandoned land across Europe: idiosyncracy or above-belowground time lags. - Oikos 103: 45-58.

Hooper, D. U. et al. 2005. Effects of biodiversity on ecosystem functioning: a consensus of current knowledge. - Ecol. Monogr. 75: 3-35.

Huston, M. A. et al. 2000. No consistent effect of plant diversity on productivity. - Science 289:1255a.

Jonasson, S. 1988. Evaluation of the point intercept method for the estimation of plant biomass. - Oikos 52: 101-106.

Kinzig, A. P. et al. 2002. The functional consequences of biodiversity: empirical progress and theoretical extensions. - Princeton Univ. Press.

Larcheveque, M. et al. 2005. Vegetation dynamics after compost amendment in a Mediterranean post-fire ecosystem. - Agric. Ecosyst. Environ. 110: 241-248.

Larcheveque, M. et al. 2006. Short-term effects of sewage-sludge compost on a degraded Mediterranean soil. - Soil Sci. Soc. Am. J. 70: 1178-1188.

Leibold, M. A. 1995. The niche concept revisited - mechanistic models and community context. - Ecology 76: 1371-1382.

Loreau, M. 2000. Biodiversity and ecosystem functioning: recent theoretical advances. - Oikos 91: 3-17.

Loreau, M. and Hector, A. 2001. Partitioning selection and complementarity in biodiversity experiments. - Nature 412: $72-76$.

Loreau, M. et al. 2002. A new look at the relationship between diversity and stability. - In: Loreau, M. et al. (eds), Biodiversity and ecosystem functioning. Synthesis and perspectives. Oxford Univ. Press, p. 294.

Maestre, F. T. and Reynolds, J. F. 2006. Spatial heterogeneity in soil nutrient supply modulates nutrient and biomass responses to multiple global change drivers in model grassland communities. - Global Change Biol. 12: 2431-2441.

McNaughton, S. J. 1993. Biodiversity and function of grazing ecosystems. - In: Schultze, E. D. and Mooney, H. A. (eds), Biodiversity and ecosystem function. Springer, pp. 361-383.

Montès, N. et al. 2004. A comparative study of aboveground biomass of three Mediterranean species in a post-fire succession. - Acta Oecol. 25: 1-6.

Pachepsky, E. et al. 2007. Consequences of intraspecific variation for the structure and function of ecological communities. Part 2: Linking diversity and function. - Ecol. Modell. 207: 277285.

Reynolds, J. F. et al. 2007. Natural and human dimensions of land degradation in drylands: causes and consequences. - In: Canadell, D. P. L. F. P. (ed.), Terrestrial ecosystems in a changing world. Springer, pp. 247-258.

Robles, C. and Garzino, S. 1998. Essential oil composition of Cistus albidus leaves. - Phytochemistry 48: 1341-1345.

Robles, C. et al. 1999. Autotoxic and allelopathic potentials of Cistus albidus L. - Comptes Rendus de l'Academie des Sciences, Serie III. Sciences de la Vie/Life Sciences 322: 677-685.

Schimel, J. P. et al. 1998. The role of balsam poplar secondary chemicals in controlling soil nutrient dynamics through succession in the Alaskan taiga. - Biogeochemistry 42: 221234.

Stevens, M. H. H. and Carson, W. P. 2001. Phenological complementarity, species diversity, and ecosystem function. - Oikos 92: 291-296.

Temperton, V. M. et al. 2007. Positive interactions between nitrogen-fixing legumes and four different neighbouring species in a biodiversity experiment. - Oecologia 151: 190205. 
Tilman, D. et al. 1997a. The influence of functional biodiversity and composition on ecosystem processes. - Science 277: 1300-1302.

Tilman, D. et al. 1997b. Plant diversity and ecosystem productivity: theoretical considerations. - Proc. Natl Acad. Sci. USA 94: 1857-1861.

Troumbis, A. Y. and Memtsas, D. 2000. Observational evidence that diversity may increase productivity in Mediterranean shrublands. - Oecologia 125: 101-108.
Van Auken, O. W. 2000. Shrub invasions of North American semiarid grasslands. - Annu. Rev. Ecol. Syst. 31: 197-215.

van Ruijven, J. and Berendse, F. 2005. Diversity-productivity relationships: initial effects, long-term patterns, and underlying mechanisms. - Proc. Natl Acad. Sci. USA 102: 695-700.

Wardle, D. A. 1998. A more reliable design for biodiversity study? - Nature 394: 30. 